Island Studies Journal, Vol. 12, No. 1, pp. 169-186

\title{
Island community: identity formulation via acceptance through the environment in Saaremaa, Estonia
}

Jana Raadik Cottrell

Kuressaare College of Tallinn University of Technology

Estonia

est.jana@gmail.com

\begin{abstract}
This paper examines normative concepts of community identity expressed by inhabitants of Saaremaa Island, Estonia, via 20 interviews of permanent residents. Community identity is discursively constructed via interpretative repertoire to examine storylines used for constructing the sense of being part of an island community. Community identity relates to infrastructural aspects (roads, bridges); islandness being a key physical, philosophical and psychological component of the island's infrastructure, followed by more specific spatial units such as parish, village, neighbourhood and home. Each infrastructural unit involves a social network and physical environment related to a continuum of normative structure. Effects of a proposed bridge to the mainland influence respondent repertoire on changes of island community identity. Acceptance was the more dominant aspect of islander identity; acceptance by/of the environment determines who-is-who on the island. Normative components of acceptance included 'bodily experience' of individuals, 'community control' and 'community signsystems.' Constructions of 'we' as islanders distinct from the non-islanders provide a complex view of community identity.
\end{abstract}

Keywords: acceptance, community, islandness, norms, place identity, Saaremaa, sense of place https://doi.org/10.24043/isj.11

(C) 2017 - Institute of Island Studies, University of Prince Edward Island, Canada.

\section{Introduction}

Place in time and space connotes more than mere physical space; there are social-psychological aspects sensed through 'actual' or 'bodily' experience of meaningful events (Shamai, 1991). Each place represents a foundation for the construction of identities. Place identity refers to the "interplay between physical attributes of the area and people's conceptions, interpretations and activities within that physical setting" (Horwitz, 2001, p. 256). Place identity is based on symbolic meanings, which translate into cognitions and beliefs; descriptive meanings rooted in symbols. Meanwhile, boundaries of place are fluid and identification with a place occurs within different spatial aspects, from a place of dwelling in a narrower sense to a geographical region in a broader context (Horwitz, 2001). Place identity processes are linked to aspects of distinctiveness as a connection to others within a social sphere or networks of an environment; the continuity describable also as bodily experience. It is this congruency between a place and sense of place as the unique nexus between the environment and individual that creates a sense of legitimacy of place for that individual (Korpela, 1989): a form of insideness as in the context of Islescapes (an idealization of home and memory bounded within an island context) as depicted 
by Peil (1999). Rowles (1983) refers to three types of insideness: physical-insideness as bodily awareness, social-insideness as knowing others and having been known and autobiographicinsideness as an idiosyncratic sense of rootedness. According to Rowles (1983) the sense of belonging to the place deepens over time as personal life stories become entangled with memories of the place. This kind of attachment to place is "intimately linked to preservation of sense of personal identity" (Rowles, 1983, p. 300).

There are two approaches to place identification: individual dimensions of place identity (Korpela, 1989; Prochansky et al, 1983) and group-based dimensions of place identification (Dixon \& Durrheim, 2000; Twigger-Ross \& Uzzell, 1996). An understanding of a shared sense of place evolves while examining group-based dimensions of place identification. Shared sense of place concerns a shared understanding of values (Dixon \& Durrheim, 2000). This context, along with a constructed community narrative and its underlying history, defines community identity (Horwitz et al, 2001). Dixon and Durrheim (2000) claim that collective identities are often presented through symbolic contrasts between "our space" and "their space". Said (1978) labeled this concept of place identification as the imaginative geography of self and others (Dixon \& Durrheim, 2000), referring to the notion that an insider within the community assumes the right to define who does and who does not fit in someone's meaningful place.

Place meanings and perceptions of community identity are subject to change along with changes that happen in the community (Horwitz et al, 2001). The discourse of values, lifestyles and overall community consistence are sources of study of social meanings and action. Cohen (1985, p. 50) states: "the symbolic expression of community and its boundaries increases in importance as the actual geo-social boundaries of the community are undermined, blurred or otherwise weakened".

Presently, Saaremaa, an Estonian island in the Baltic Sea, is in a stage of transformation. Discussions to connect the island to the mainland by bridge have reached a stage of confirmation. The era of relative isolation as an island will soon be over. The bridge is viewed as part of a larger development plan; the first stage, a deep sea port on the west coast of the island, was constructed in 2007, after some years of debate over its environmental impacts. The port, planned initially for cruise ships and providing a layover for international cruisers as a side trip to St. Petersburg, Russia, is currently being transformed into a cargo harbour. As one of the few icefree ports on the Estonian coast, together with the bridge, Saaremaa could become an attractive multiple-use transportation route.

Saare County was chosen for this study due to its present situation and expected change in sense of belonging and place identity among islanders due to a proposed development. The proposed bridge and port construction provide a unique opportunity to collect baseline data in place identity pre-construction and then to monitor changes after the development is completed. The time of island development under study was unique due to its transformation from 50 years of a relatively closed community to a place with blurred boundaries both physical and psychological. The island as a relatively closed society is sensitive to large developmental projects and expected change is expressed with concern. Expected change is important to place attachment and sense of belonging, since it psychologically remains an area of experience largely unknown (Relph, 1976; Twigger-Ross \& Uzzell, 1996). Previous studies call for further investigation of changes in physical environment and threats to place identity with a focus on place disruption (Twigger-Ross \& Uzzell, 1996). 


\section{Purpose}

This paper investigates community identity as expressed by inhabitants of the local community within the context of rapidly transforming identities. Community identity refers to large-scale (regional) collective identity, which is continually produced and reproduced in discourse by positioning processes and social categories under construction. Norms are part of each community: any informal culture will provide norms governing member perceptions of how reasonable it is to depart from the norms salient to that culture (community) and how other people of that community will react to those departures (Stamper et al, 2000).

Differences between native and residential islanders' perceptions of community norms, as well as their related subgroups for and against major developmental plans, will be discussed.

\section{Theoretical context of place identity}

Several authors stress the importance of long-term commitment and experience to attach or identify with a place (Relph, 1976; Tuan, 1977, 1980, 1991). Place identity concepts, advanced by Prochansky et al, Fabian and Kaminoff (1983) and Korpela (1989), were described as part of identity process theory (Twigger-Ross \& Uzzell, 1996).

Many studies of community identity call for a more discursive rather than a functionalist approach (Colombo \& Senatore, 2005; Dixon \& Durrheim, 2000; Rapley \& Pretty, 1999). Functionalists examine community identity from two main approaches: one grounded in a territorial-based conception while the other refers to a social-network relationship. Places undergo constant change while the identity concept, as an enduring one, remains open to modifications over time (Horwitz et al, 2001). Dixon and Durrheim (2000) argue that this aspect of place has been missing in past research of place identity. Their work focuses on the rhetorical traditions of place, the marginalized political dimension of representations of place and the localization of individuals in relation to others, referred to as the 'displacement' of place identity.

The theoretical basis of a discursive perspective lies in semiotics and post- structuralism and from this perspective community identity is considered a socially constructed notion intended to give meaning to experience (Colombo \& Senatore, 2005). A discursive perspective embeds a major shift from the view of language as a simple tool of description and medium of communication to understanding its role as social practice (Colombo \& Senatore, 2005). "The 'quality' of place is more than aesthetic or affectional; it has a 'moral' dimension as well, which is expected for language as a component in the construction and maintenance of reality. This alludes to understanding how people intersubjectively construct and negotiate their notion of community (Colombo \& Senatore, 2005; Dixon \& Durrheim, 2000; Rapley \& Pretty, 1999; Stamper et al., 2000), as well as an understanding of the social structure of an island in order to understand the sites of conflict and hidden symbols used in different situations (Gibbons, 2010).

Since place identity and community identity are meaning-based concepts rooted in beliefs and attitudes, attitudinal research is applicable to investigate the normative aspects of these phenomena. Research has shown that identity salience will lead to behaviours consistent with identity, primarily situating identity in the theory of reasoned action/planned behaviour (Stedman, 2002). Since behaviour can be identified as substantive or semi-logical, the role of signs cannot be underestimated as vehicles of extending actions in temporal and spatial dimensions (Stamper et al., 2000). According to Stamper et al. (2000), any social group needs three kinds of norm-governed behaviour: self-referring behaviour, learning and interaction. The process of interaction as constant interpretation calls for a need to understand signs as united 
components of norms. Charles Sanders Peirce (1934), concerned with the structure of meaning in total human experience, stresses on the importance to understand 'semiotics' as both verbal and non-verbal systems of signification. Peirce (1934) suggested that the meaning is derived through the triadic interactive relationship among the designatum (signified concept/object), the sign (the signifier used to represent the object/concept) and the interpredant (the one interpreting the sign). Pierce's interpretation of sign systems recognizes signs as not only standing for something, but as standing for something to somebody (Echtner, 1999). Using Peirce's semiotic triangle as an analytical frame to understand how a person constructs one's self as a member of community, the interpreter must have knowledge of a norm in order to associate signs with objects (Stamper et al., 2000). Successful communication of community norms requires analogous interpretation of signs from all community members.

Symbols and signs are mechanisms of a collective memory. The memory of a sign is always more ancient than a memory of the environment from which it is derived (Lotman, 1999). Thus, working as memory of a culture, signs do not allow culture to be demolished (Lotman, 1999). Lotman (1999) also emphasizes that, even if we do not know the symbols of a culture, the culture itself is aware of its signs and symbols.

The literature in environmental and social psychology addresses many issues of identity processes, both individual and collective, with more focus between the different identity-related processes and environmental perceptions (Devine-Wright \& Lyons, 1997; Dixon, 2000; Horwitz et al, 2001; Liepins, 2000). Sudden transformation of valued place brings up notions reflecting the 'dislocation' of identity. Making connections to the identity aspects, Dixon and Durrheim (2000, p. 38) referred to it as "disturbance of ecological-self" and "disruption of one's social inside-ness", thus "the loss of place referent continuity provides the ethical grounds for criticizing the changes".

The loss of identity or major damage to identity on a personal or group level, as a result of major environmental change, has been the focus of many studies (Bonaiuto et al., 1996; Carrus et al., 2005; Devine-Wright \& Lyons, 1997; Dixon \& Durrheim, 2000; Stedman, 2002; Vorkinn \& Riese, 2001). Empirical evidence has shown linkages between socially more cohesive communities with a stronger sense of social and place identity and environmental concern (Bonaiuto et al., 1996; Stedman, 2002; Gibbons, 2010; Vorkinn \& Riese, 2001). Carrus et al. (2005, p. 241) claim that "threats to people's social identities should be responded to by increased attempts to differentiate the in-group positively from out-groups" and they continue similarly, transposed at the level of place when the social identity referring to nationality (or region) is salient in the context. Nationalism (or local identity) form the basis of environmental perceptions and evaluations, which could be in-group/out-group stereotypical and normative (Bonaiuto et al., 1996; Carrus et al., 2005).

Carrus et al. (2005) also claim that such a threat to territorial continuity and place-related identity might reinforce place attachment. Place attachment is "most profound when human relationships are embedded in current or past group affiliations and identity" and it "becomes more intense when the identified groups are in clear juxtaposition to an out-group which functions as a threat" (Fried, 2000, p. 195).

The importance of isolation and separateness has been stressed as an important historical aspect to determining an islander's identity, both from a personal and community perspective. The literature concerning islands refers to topographical isolation as a key element of identity and islander mentality (Clark, 2004; Gibbons, 2010; Kelman, 2003; King, 2009; Lehari, 2002). King (2009) writes about the many metaphors of insularity linked to the many 
types of migration, with the interactions far from simple. Lehari (2002) distinguishes between two types of islander identity, namely sea and land identity (those people more closely linked to the sea versus those linked to the land). These are certainly not the only identity types, yet each represents a primary type of island lifestyle that makes it possible to understand the particulars of an islander's life world (Lehari, 2002).

This paper identifies and explores community identity repertoires and their use among residents in a local community. Secondly, the study investigated how repertoires were used to describe, explain, justify and evaluate different identity constructions in a situation of substantial change in both environmental and community identity-related normative components.

\section{Methodology}

\section{Study area}

Saare County is located on islands in western Estonia (Figure 1), covering 7\% of Estonia's land area, some $2,922 \mathrm{~km}^{2}$. The larger islands are Saaremaa and Muhu, which are connected by a causeway. Throughout history these islands have been independent from the mainland not only physically, but politically and economically as well. During Soviet times this area was a restricted border zone for nearly 50 years. Its previous history of relative isolation has led to perceptions of this island community as safe, independent and to some extent exotic (Raadik, 2005).

\section{Figure 1: Location of case study area, Saare County in Estonia.}

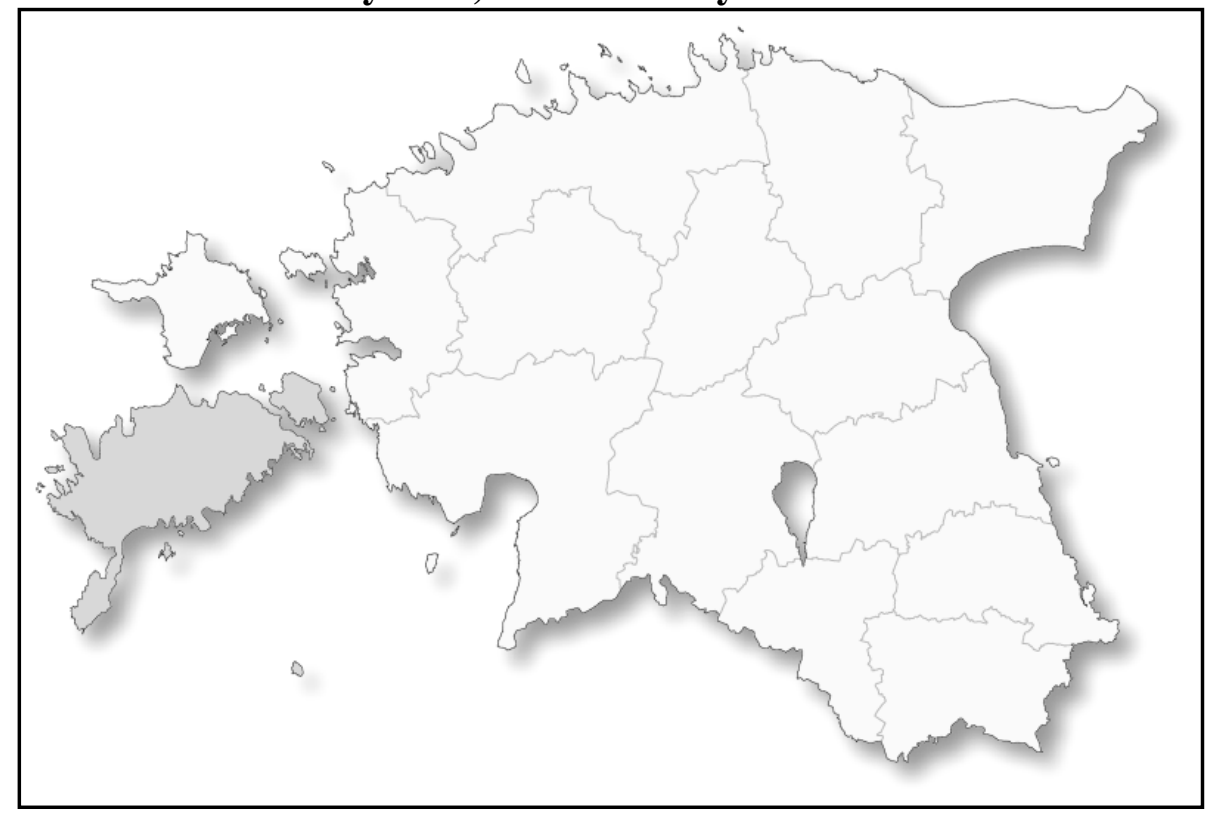

Rapid development during its renewed independence after the Soviet era changed the economic situation and social structure on the islands dramatically. Presently, the island community is among the most entrepreneurial in Estonia, yet considered a peripheral area to the mainland. Fifty years of being a restricted border zone has shaped islanders' mentality, raising questions of weakness and vulnerability of the island community in all of its infrastructural 
aspects. A bridge to the mainland is expected to maintain and enhance the quality of life on the islands (Raadik, 2005).

Due to its location on an island, Saare County has certain advantages and disadvantages over counties on the mainland. Saaremaa's greatest riches are its clean, unique and diverse natural environment and safe community. The islands' weaknesses include their restricted economic and social development opportunities as well as limited work opportunities and an aging population (Raadik, 2005).

\section{Sample}

The study is based on in-depth unstructured interviews with 20 people from the islands of Saaremaa and Muhu in Saare County, Estonia. The objective of the study was to acquire deep knowledge of interviewees' life experiences (Johnson, 2001). Strategic non-representative sampling was used to obtain a wide range of variation in responses (Trost, 1986). Interviewees were recruited through personal contacts. The choice of interviewees was guided by two criteria: 1) to capture a broad socio-economic background in age, gender, education, dwelling (living in the city or countryside) and occupation; and 2) to represent different family roots as islanders, from native islanders to residential (second-home owners and/or coming-for-work) islanders. It was important to select people with different life paths (also different mobility patterns) to obtain a diversity of experiences and perceptions of life on the island and ideas about islanders' identity. Coming from Saaremaa, the author is socially connected to the life and ways of the island, which aided in the final selection of people to interview. Meanwhile, as Gibbons (2010, p. 171) notes, "an understanding of the rough social outline of the island is necessary to understand the sites of conflict and hidden transcripts employed in different situations", is necessary and my connection to this island allows for that understanding. It is definitely different to be a researcher in your own community, the insider in critical ways (Dowling, 2000; Narayan, 1993; Porteous, 1988). Yet, being in your own community means to be an outsider concurrently as well (Narayan, 1993), which is a challenge itself (Baldacchino, (2008). Our places can become too familiar, and not everything opens up for us anymore (Porteous, 1988). Being an insider, researchers study place through themselves as well; places become incorporated into them and created through them (DeLyser, 2001; Nast, 1998). As Baldacchino (2008) notes, few island studies are conducted by native islanders; the present paper seeks to serve as a corrective to this tendency.

\section{Data collection}

Open interviews averaging 90 minutes were conducted between November and December 2004 for a Master's thesis project (Raadik, 2005). Conversations about the Saaremaa bridge project have gathered momentum in recent years, thereforel influencing the decision to revisit the 2004/2005 data as baseline data pre-bridge construction. Interviews were taped with verbatim transcripts in Estonian. Only those statements included in this paper were translated into English. It should be noted that translation from Estonian to English could be a limitation due to a certain degree of loss of meaning via translation. As an author and native Estonian I claim proper transferability of the data (Decrop, 1999).

Analysis

To understand how the community identity is discursively constructed, the notion of 'interpretative repertoire' (Potter \& Wetherell, 1987) was used to examine storylines interviewees practiced for constructing their sense of being part of an island community. 
Interpretative repertoires refer to the building blocks interviewees use for constructing versions of actions and cognitive processes (Wetherell \& Potter, 1988). Assuming that identities are discursively constructed, various meanings of community identity can be expected.

Discourse analysis is characterized by the adoption of an inductive approach which does not use categories defined a-priori (Colombo \& Senatore, 2005). Rapley and Pretty (1999, p. 698) stress that the "employment of a-priori analytic category system is neglectful of local contexts and imposes theoretically-rather than locally - derived structures of meaning and relevance". To understand how community identity is discursively constructed, an interpretative repertoire was applied with emergent coding to search for themes related to norm construction. Discourse analysis attempts to study variations in content to work towards an understanding of function. By studying the resources from which an account was constructed enables us to investigate what it might achieve (Wetherell \& Potter, 1988).

Results are presented as a storyline interlinking empirical results with related theory to clarify meanings to islander statements. As an islander I occasionally add my own illustrative narrative yet I limit my own storyline to avoid detracting from the interviewee's perspectives. Direct quotes are assigned to pseudonyms in order to protect the anonymity of respondents.

\section{Results}

\section{Territorially based community: micro and macro level identities}

Every landscape is a cultural product as a symbolic property of a particular community, with its own history and values. The same holds true for Saaremaa, where aesthetics link to ethical and socially legitimated categories in its 'morphology': such as we-others, known-unknown, goodbad, beauty-ugly, (Brocki, 2004). While making distinctions between 'own' and 'others', the island landscape and broader context of the whole island environment (in its natural, sociocultural and political expression) was set as the background to serve as the basis of reflection.

Saaremaa has long been separate, territorially and for a long time politically, and that separateness has formed a distinct sense of 'self' among islanders. Facing the sea and its dynamic nature, islanders through history could not count on anyone but themselves. The need for selfsufficiency was mentioned as a reason why islanders clearly make the distinction between 'us' and 'them'.

Lehari (2002) argues that the opposition between 'own' and 'aliens' is weaker on the island than in other areas of mainland Estonia. This is explained as a higher sense of selfconfidence and stronger place identity, which enables a wider openness, openness to respect others because of their otherness, although the latter are not easily accepted as part of the community (Lehari, 2002).

The interviewees expressed the same feelings about the openness of islanders in respect of otherness, but noted opposition between own and alien as one of the main characteristics of islanders in their social relationships, and that being much stronger than on the mainland. This opposition was not considered antagonistic, but strongly present in the acceptance of people arriving from outside the island, considered non-native or as newcomers. One respondent commented:

The lack of acceptance, distinction between us/them is surprising [...] but, nothing unpleasant $[\ldots]$ people are more reserved or withdrawn, not everything is said out 
loud. Things just are like they are. You have to live in this environment to understand it. MM

Place of dwelling as a means of a discursive construction of community identity can help explain local identification at a micro-level of identity, such as neighbourhood or village, or macro-level such as the island community. These are characterized as specified dimensions of distinction, yet connected levels of territorially based identity (Colombo \& Senatore, 2005). Islanders in this study did not consider place of dwelling as an identification source on a micro-level uniformly connected with identification on the macro-level or opposite. With respect to local micro-level identification, nine native islanders defined themselves according to their place of dwelling (village), while four identified more with their place of birth or ancestral connection. Native islanders $(n=3)$ who were more negative about the bridge were more likely to connect locality with their roots (birthplace, 'home-place') with its historical-temporal continuity (see Table 1).

Table 1: Number of respondents who defined themselves as locals or non-locals according to their place of dwelling $(\mathrm{N}=20)$.

\begin{tabular}{|l|c|c|}
\hline Interviewees & Local & Non- local \\
\hline Native islanders $(\mathrm{n}=13)$ & $9(1)$ & $4(3)$ \\
\hline Residential islanders $(\mathrm{n}=7)$ & $6(3)$ & $1(1)$ \\
\hline
\end{tabular}

Numbers in parenthesis indicate number of respondents who disapprove of the fixed link.

For example, one islander stated:

I am not a local. I am on a long-term duty assignment (laugh). My birthplace is in Kaarma parish (note: Saare County). MM

You can live in the place but never be accepted as local. Roots go to customs. If a man marries a woman from another county or parish, she can never wear the local national costume. She must wear her own parish one, till the end of her days. MM

This statement alludes to historical-temporal continuity or an awareness of a territorial continuity. The core aspect of this notion is rooted in a territory with a mythic-emotive call of being an 'islander'. This illustrates a shift from the idea of place as the context of life and residence to place as an origin, which supports Colombo and Senatore's (2005) arguments.

Residential islanders were more liberal and identified themselves as locals according to their place of residence. This difference between native and residential islanders in their identification patterns on a micro-level lies in the dissimilarity of defining micro-level identity. On a micro-level, residential islanders focused more on the importance of their local social networks as an identification source than did native islanders.

The normative aspects of identification of self as part of the island community (macrolevel identity) were more salient among islanders. As indicated by studies of island communities (Clarke, 2004; Devine-Wright \& Lyons, 1997; Gibbons, 2010; Kelman, 2003), the island can be seen as the mainland's synecdoche. From the aspect of identity and communal feeling, an island could be considered an ideal model of a small-scale society. "Its own products, leaders and institutions have been the objects of continuous social interest and control" (Lehari, 2003, p. 97). Insularity as a main aspect of differentiation from the 'others' was uniformly held among 
islanders. This 'island identity' was associated with a notion of 'nationality'. Respondents in this study noted:

I think this separateness is somehow in the genes [...] that water is around you [...] I like to be separate. $\mathrm{LH}$

Isolation has created islanders' mentality and habit of mind, mine too [...] TP

The identity of an islander is formed by an island, the insularity [...] man is proud, it is like nationality. BP

The islanders also appreciated the importance of a generic, global sense of islander identity, of which they partook:

Islanders everywhere are more open $[. .$.$] it is easier to communicate with them [\ldots]$ you feel the mutual bonds. MM

There must be some kind of islanders' mutual identity [...] I met one of their kind somewhere, they are happy to see each other. It is not common with the mainlanders. OP

Islanders have that certain identity and you are happy to see other islanders [...] you cannot recognize them from first sight maybe, but when you start the conversation. It is that same way of thinking among all the islanders and people from the coast [...] the sea connects them, but islanders have even something more, this isolation. TP

The interplay between spatial networks of place and networks of people is balanced by regulations that only time can create. The longer a place's historical memory, the stronger its community identity. As mentioned before, time of residency on the island was considered a main factor for local identification, which has a strong connection with a specific place and its level of relative isolation. In the island environment of Saaremaa, full acceptance by the community still requires knowledge about inhabitants regarding ancestors, lifespan and their monitored movements:

The hold to the place comes through history [...] my ancestors are important for me. It is about the feeling of belonging. All that layer of history makes me feel peaceful. VV

Everything will disappear or diminish without the input to maintain [...] the ancestors are the answer to many questions, their way of sustainable living, living with nature. LT

History gives answers to most problems [...] also to the question of identity. VV

Background investigation is part of community approval. Knowledge about your roots is important. KP 
The importance of a 'home-place' was prevalent and a majority of islanders stressed the perceived importance of roots to be accepted as a 'full-blooded' community member:

It is a long and complicated way to become an islander. I am not yet, but I want to be. EL

I am an islander who was born outside the island. I had nothing to do with that [...] but in my heart I am islander. VV

A 'true' islander? I do not know [...] I was born here, but my father is an outsider. $\mathrm{TP}$

Islander [...] maybe not [...] I have lived here for only 30 years. OP

This discourse alludes to acceptance of a person by the environment. Table 2 shows the identification patterns that evolved from the acceptance theme. A majority of native islanders perceived themselves to have been accepted by the island environment. Residential islanders were more moderate in their expressions about acceptance by the environment. This perceived inability to comply with a 'perceived social norm' did not allow them to identify with the community due to a different place of birth. Some found the lack of acceptance merely as something one should cope with when living on an island; some did not see it as being important at all. Meanwhile, three residential islanders felt accepted by the environment and considered themselves as belonging to community, with the added notion of distinction: not as a 'true islander'.

\section{Table 2: Perceived acceptance expressed by native and residential islanders $(\mathbf{N}=\mathbf{2 0})$.}

\begin{tabular}{|l|c|c|c|}
\hline Interviewees & Total & $\begin{array}{c}\text { Acceptance by } \\
\text { environment as islander }\end{array}$ & $\begin{array}{c}\text { Acceptance of island } \\
\text { environment }\end{array}$ \\
\hline Native islanders & 13 & $12(6)$ & $12(7)$ \\
\hline Residential islanders & 7 & $3(1)$ & $6(4)$ \\
\hline
\end{tabular}

Numbers in parenthesis indicate number of respondents who disapprove of the fixed link.

The discursive approach to community identity is important. Notions from residential islanders as 'being accepted by the environment' despite the 'norms' of acceptance are explained by changing environments and blurred boundaries of community identity. Changing environments are about the renewal of communities: the community and its identity is in a constant state of change. When changes take place in too short a time and are not considered a natural part of development and evolution, they call for a discussion of changed community identity. In more normal development, processes of change can be sustainable and may be viewed as a force of rejuvenation and renewal. 'Bodily experience' refers to knowledge of coping with the environment and cannot be abstractly structured or merely learnt; it requires physical experience. Bodily experience or person-setting relationships reveal the full significance of place identity, defined occasionally as a psychological structure of which people are only partially conscious (Dixon \& Durrheim, 2000). Thus, it cannot be delimited to a notion of 'time of residency'; it requires a more discursive approach of constant involvement in a specific set of relationships. 
This makes the distinction between 'individualism' and 'desire to maintain anonymity or separation' from active creation of bonds with one's environment more clear. This finding is supported by previous discursive studies of community identity (Colombo \& Senatore, 2005; Dixon \& Durrheim, 2000). Several native islanders were conscious of the inevitable changes to the island environment and believe that the desire to become an islander is possible through 'bodily experience', an expression that involves respect of the environment in all its aspects.

I believe that knowledge of living on the island grows into the person [...] it is easier for a person who was born on the island. There are things a person experiences bodily from childhood, such as how to survive on the island. KT

Sea identity-land identity

Although not sharply distinguished, the elements of sea identity versus land identity are noticeable in the self-description of islanders and in their mentality. In their comments about the essence of being an islander, respondents mentioned the importance of the sea as the marker of their distinction from 'others':

People living by the sea and far away from it are different [...] the essence of lifestyle, that natural background, so mobile and unstable, forces man to react quickly, to possess riches in nuance sense of life, to be in contact with everything you are involved with [...] Lifestyle of a man of land is routine, familiar daily, monthly [...] the life of a man living by the sea is totally different. This unexpectedness, constant moment of surprise from your environment demands standby to all variances [...] this need of mobilization, the need to be somebody every day, maybe a bit more grateful as you really are; this is one of the riches of islanders. JT

Life by the sea demands more carefulness, economy and providence-no need for luxury. Live yourself and let others live, that's the rule of life by the sea $[\ldots]$ a man takes what the sea gives, even if it is cruel sometimes. The value judgments on the island are more straightforward, but you cannot live here otherwise. JT

Here on the island is more spirituality compared to the mainland [...] yes, the mental well-being is more important than material. MM

Living by the sea $[\ldots]$ that sense of place is hard to describe. For me people living on island are like people in Alaska [...] more convenient would be to live in New York, but they live in Alaska. MM

Islanders have stronger inner worlds and this reflects a healthy environment. Islanders have that fairness towards their fellow man. You cannot find it anymore outside. KP

Islanders have different value judgements. They are more trustful. Trustfulness is like a symbol of islanders among mainlanders. Yes. To be true, myself, I trust also islanders more. MM 
Interviewees mentioned isolation as a means to mobilize islanders to defend their interests on a large scale, but much more rarely at the micro-level of interest like citizens' rights. References to a closed society and stubbornness created by the sea environment were referred to as causes among members of the community to not show off their personal ambiguity, but to adjust themselves to changes in the environment and accept them as natural. Thus, the notion of acceptance has another connotation: acceptance of the environment by a person:

I will always try to arrange my life according to changes in the environment; I am not a global fighter. I will try to adjust myself to the background. MM

Life here requires that you are used to your limitations, accept it and take it as natural. KT

The island environment sets its limitations to movement patterns both inside and outside its borders. To live in a demanding environment, with the limited resources that the island offers, demands knowledge and acceptability of a different type of lifestyle. The constant need to be alert and ready for change sets another mood commonly shared and understood by islanders. Respondents mentioned notions like 'living with the environment', 'being patient' and 'observable' as an environment sets its own mood and pace; thus making people in it wanting to follow another passage of time where prevalent. Island space descriptions often emphasize the different time paths, such as "time standing still" or "going back in time and space" as a sort of slower passage of time. The speeding-up world versus time standing still was a distinction made between outside worlds (mainland perspective) versus the island world. The slower passage of time was seen as a time facilitator to see more and up closer. This aspect resembles the functionality of infrastructural space on the island, both social and environmental:

Life on island is slower and the worries of people are more noticeable [...] lower speed facilitates the ability to observe and see more. KA

Locals do not hurry. They seem to have more time. People talk about the wind. TO

An islander takes his time. The time needed to deepen into the thoughts, conversations and activities. EL

Most of the respondents tend to accept the island environment as described above. Results imply that, even though respondents considered their environment as offering more positive than negative aspects in its relative isolation, five native islanders from those accepting the island's environment in general favoured the idea of a bridge versus two residential islanders. The residential islanders expected more newcomers to the community, while native islanders saw profit in their personal 'sense of freedom' or showed indifference while referring to adjusting themselves according to change. One native and one residential islander evaluated the island environment less favourably than the outside environment and considered their life on the island as a temporary stage. 


\section{New communities}

The use of environment is one indicator of the 'us' versus 'them' differentiation; collective identities are signalled through environmental practices (Dixon \& Durrheim, 2000). One of the respondents explained her feelings of belonging to the local village through the mundane everyday practices:

There is a lot of stress on connections between people while talking about locality and identity, but those signals about being local or not come through the environment from the use of the natural and built environment or more precise misuse. It is so easy to say from environmental behaviour who is local and who is not. People are not maybe even aware, but it is like when you rake your leaves from the garden in the autumn you are a local. When you do it in the spring you are not. KT

Many respondents were concerned about construction of new 'communities' in places where place identity would be weakened due to a decrease of local residents below a critical number of residents necessary to maintain the identity of place. Comments like "place identity will collapse, when people who put up with it will disappear"; "social care keeps places alive, since the older members are identity carriers" and "we need the older people or people here long enough [long term permanent residents] to replace them":

Violence towards the environment is possible only in those places were the community control is weakened over the critical point or totally diminished. KT

Islanders perceive threat from 'new communities' differently. Those islander respondents who are more positive about the bridge stressed the inevitable change they foresee in the island's environment; the bridge is not viewed as a threat to 'perceived island identity'. Their arguments evolved from a more eco-centric view of the dominance of nature over humankind and nature's ability to cope with change:

New life brings new people with their new identity. We must take things from a stoic rationale. Nature is more powerful and endures more change than humans; it does not care $[\ldots]$ other time, the other life $[\ldots]$ for other people. JT

Reference to movement patterns on the island was noted as a perceived 'community norm' with identifiable differences among native islanders who were either supportive or not supportive of change in accessibility. Interviewees supportive of the bridge referred to such aspects as to gain 'relief' from a perceived pressure of community control over patterns of individual movement, to a sense of 'more personal freedom' and 'anonymity' if a bridge was built. They stressed that getting off the island by ferry to the mainland takes a lot of time (more than a bridge would). Ferry access was referred to as a time constraint or limitation and a bridge would make a noticeable difference.

The rate of acceptance was viewed as an indicator of stability or change of regional identity:

Island identity is a lot about us versus them relationships [...] acceptance of newcomers in the community; this resembles a form of hidden resistance. I think for 
community identity, that acceptance is a means to keep regional identity alive. There will always be local people with local memory and a local way of acceptance of other people. KT

Rate of acceptance was also tightly connected with the notion of community control. Community control and social care were referred to as aspects of maintenance and continuity of community identity. Community control was valued as positive, although a little stressful at times:

It seems sometimes a little irritating, but $[\ldots]$ it is like a protective mechanism to secure the local identity [...] the community control and knowledge. KT

The sign systems of community

The importance of communication was mentioned several times with reference to 'others'. Islanders do not have a problem communicating among themselves; it is more a matter of communicating with outsiders. The knowledge of behaviour, what is accepted on the island and not maintained via community control through sign systems, tends to be accepted by locals. Local sign systems are often unreadable to outsiders, referred to as 'others':

It is our virtue and strength to understand and perceive what is worth doing and saying out loud. We are strong until we have not lost our feeling of shame [...] what is accepted and what is not on our island. This is the way we do or say [...] If you can understand that, you will understand a little more about us as an islander. EL

Local people know how to communicate between themselves, but when it comes to others [outsiders], it gets bad. KT

These signs of being part of an island community are both material and immaterial in nature. Material signs are embedded in environmental use or material artefacts such as architecture. Immaterial signs of island community were noted as humour and language.

Humour was and is used to find out about another person. An adequate response to a joke is a key to identification. Humour is a litmus test. JT

The language here substitutes the ancient feeling of home for me. JT

The language of islanders, its singing character, its non-aggressive character; in that [in language] is the respect to opponents and life in general. JT

Saaremaa has that special feeling, what is lost elsewhere in Estonia. Attitudes and something in the air: free, casual, humorous, non-aggressive, non-demonstrative, favourable, banter, humourist introspective. MM

Lotman (1999) implies that signs are more stable than the environment they originate from. Interviewees mentioned how meanings of signs remained the same when objects they were related to have changed. Those signs were understood as symbolic, salient to a community as a form of communication tool. 
In the old times, people put the broom in front of the door as a sign that nobody is at home [...] they still do, but now the door is also locked [...] for security. But it is a sign $[\ldots]$ now more as a symbolic one. MM

References were made to the need for an adequate sign system to use as a communication tool during a time of dramatic change in the complex social system of the island environment:

Local humour and systems of habit and values should be interpreted as part of a sign system made understandable for outsiders. This would be a serious assignment for semioticians and psychologists [...] it would be a tool for locals to communicate our values and understandings to prevent the processes of lost control over our identity processes. KT

\section{Discussion}

This paper addresses different aspects of community identity as expressed by respondents. At a semantic level the notion of community identity embeds elements such as 'island identity', 'local identity', 'acceptance', bodily experience', 'community control', and 'community sign systems'. The various facets of the repertoire provide a complex view of island community identity. Respondent discourse is characterized via "a set of discursive strategies for safeguarding not just the distinctiveness and uniqueness of the in-group, but its internal homogeneous as well" (Colombo \& Senatore, 2005, p. 59). As part of the discursive approach, different linguistic procedures are used in the construction of 'we' as a distinctive group from 'other' (Brocki, 2004; Colombo \& Senatore, 2005; Rapley \& Pretty, 1999). In this construction, reference points shift from the more abstract to the more specific; from a narrative to direct action. Each construction implies a type of criteria for inclusion/exclusion being specific and restrictive in context (Colombo \& Senatore, 2005). According to study findings, the concept of 'we' refers to the following constructions of identity:

- the local residents sharing the island environment;

- the local residents accepted by island environment (gained from historic-temporal continuity);

- the local residents accepting the island environment (gained from 'bodily' experience);

- the local residents as interpreters of the local sign-system.

Study participants expressed different infrastructural units as sources of identification. The various levels of local identity show the primacy of the parish as a 'true' identifier inside and outside of the island space and villages as micro-units of identity. Villages and parishes are the foundation for the continuity of identity as sources of rootedness that have a deep historical background. Community control evolves from those units and are perceived important to the identity-forming process.

Findings from this study about micro- and macro-level identity were not consistent with findings from similar studies about community identity (Colombo \& Senatore, 2005; Cuba \& Hummon, 1993) where macro-level identity was more 'distant' and less salient as a dimension. Island community as stressed by islanders was expressed as an extremely salient identification source as well as a source of more general personal well-being in the present situation; a situation 
where historical micro-level identification units (village, parish) rapidly change with boundaries becoming increasingly blurred.

Community control leads to acceptance, referred to as a crucial element of island community identity. Acceptance was found to be one of the more dominant aspects of islander identity. Acceptance by the environment and acceptance of the environment determines 'who is who' in the island space. Acceptance by the environment is difficult to achieve as roots were noted as important to a sense of belonging, thus impossible to change at the personal level even with good intentions. The changes in environment (due to present developmental plans) may change the present situation when 'new communities' become dominant and acceptance by the environment loses its social relevance. The maintenance of community identity could be cultivated through the creation of a 'sign system' as a modified version of community control, readable across different cultures. Thus, it might work in situations where merely 'coping' with community identity by newcomers is threatening to become a form of 'new community' identity.

Future research about island community identity could examine a broader analysis of naturally occurring discourse. Sense of place and place identity could be further examined within the context of Islescapes, a term coined by Tiina Peil (1999) in her study comparing Estonian apprehension of landscape bounded by islands and the sea with the associated memories. Study of records of natural interaction in island settings (such as local newspaper articles and online forums related to them, and records of institutional functions such as village meetings) as well as interviews with 'cottagers' ('newcomers') can bring new insights to this inter-subjectively produced meaningful place: 'an island'.

\section{References}

Baldacchino, G. (2008). Studying islands: on whose terms? Some epistemological and methodological challenges to the pursuit of island studies. Island Studies Journal. 3(1), 37-56.

Bonaiuto, M., Breakwell, G.M., \& Cano, I. (1996). Identity processes and environmental threat: the effects of nationalism and local identity upon perception of beach pollution. Journal of Community \& Applied Social Psychology, 6, 157-175. https://doi.org/ 10.1002/(SICI)1099-1298(199608)6:3<157::AID-CASP367>3.0.CO;2-W

Brocki, M. (2004). Landscapes of memory; narratives of the past places. Paper presented at the Culture, Nature, Semiotics: Locations IV, Tallinn-Tartu, September 23-26.

Carrus, G., Bonaiuto, M., \& Bonnes, M. (2005). Environmental concern, regional identity, and support for protected areas in Italy. Environment and Behaviour, 37(2), 237-257. https://doi.org/10.1177/0013916504269644

Clark, E. (2004). The ballad dance of the Faeroese: island biocultural geography in an age of globalisation. Tijdschrift voor Economische en Sociale Geografie, 95(3), 284-297. https://doi.org/10.1111/j.1467-9663.2004.00308.x

Colombo, M., \& Senatore, A. (2005). The discursive construction of community identity. Journal of Community \& Applied Social Psychology, 15, 48-62. https://doi.org/10.1002/casp.809

Cohen, A.P. (1985). Symbolic construction of community. Hemel: Ellis Horwood. https://doi.org/10.4324/9780203323373

Cuba, L., \& Hummon, D.M. (1993). A place to call home: identification with dwelling, community and region. The Sociological Quarterly, 34(1), 111-131. https://doi.org/10.1111/j.1533-8525.1993.tb00133.x

Decrop, A. (1999). Triangulation in qualitative tourism research. Tourism Management, 20, 157- 
161. https://doi.org/10.1016/S0261-5177(98)00102-2

DeLyser, D. (2001). Do you really live here. Geographical Review, 91(1/2, Doing Fieldwork), 441-453. https://doi.org/10.2307/3250847

Devine-Wright, P., \& Lyons, E. (1997). Remembering pasts and representing places: the construction of national identities in Ireland. Journal of Environmental Psychology, 17(1), 33-45. https://doi.org/10.1006/jevp.1996.0037

Dixon, J., \& Durrheim, K. (2000). Displacing place-identity: a discursive approach to locating self and other. British Journal of Social Psycholology, 39(1), 27-44. https://doi.org/10.1348/014466600164318

Dowling, R. (2000). Power, subjectivity and ethics in qualitative research. In I. Hay (Ed.), Qualitative research methods in human geography (pp. 23-36). South Melbourne, Australia and New York: Oxford University Press.

Echtner, C.H. (1999). The semiotic paradigm: implications for tourism research. Tourism Management, 20, 47-57. https://doi.org/10.1016/S0261-5177(98)00105-8

Gibbons, M.S. (2010). Islanders in Community: Identity negotiation through sites of conflict and transcripts of power. Island Studies Journal, 5(2), 2010, 165-192.

Fried, M. (2000). Continuities and Discontinuities of place. Journal of Environmental Psychology, 20(3), 193-205. https://doi.org/10.1006/jevp.1999.0154

Horwitz, P., Lindsay, M., \& O'Connor, M. (2001). Biodiversity, endemism, sense of place and public health: interrelationships for Australian inland aquatic systems. Ecosystem Health, 7(4), 253-265. https://doi.org/10.1046/j.1526-0992.2001.01044.x

Johnson, J.M. (2001). In depth interviewing, in J. Gubrium and J. Holstein (Eds.) Handbook of interview research: context and methods. Thousand Oaks: Sage. https://doi.org/10.4135/9781412973588.n8

Kelman, I. (2003). Managing vulnerabilities of small island heritage. Retrieved from http://www.arct.cam.ac.uk/islandvulnerability/IlanKelmanArkellReport.doc

King, R. (2009). Geography, islands and migration in an era of global mobility. Island Studies Journal. 4(1), 53-84.

Korpela, K. M. (1989). Place-identity as a product of environmental self-regulation. Journal of Environmental Psychology, 9, 241-256. https://doi.org/10.1016/S0272-4944(89)80038-6

Lehari, K. (2002). On island. Place and Location. Studies in Environmental Aesthetics and Semiotics, 3, 95-106.

Liepins, R. (2000). New energies for an old idea: reworking approaches to community in contemporary rural studies. Journal of Rural Studies, 16(1), 23-35. https://doi.org/10.1016/S0743-0167(99)00042-X

Lotman, J. (1999). On semiosphere. Tallinn, Estonia: Vagabund.

Narayan, K. (1993). How native is "native" anthropologist? American Anthropologist, 95(3), 671-686. https://doi.org/10.1525/aa.1993.95.3.02a00070

Nast, H. J. (1998). Body as "place": Reflexivity and fieldwork in Kano, Nigeria. In H. J. Nast \& S. Pile (Eds.), Places through the body (pp. 93-116). London; New York: Routledge.

Peirce, C. S. (1955). The theory of signs. Philosophical Writings of Peirce. New York: Dover.

Peil, T. (1999). Islescapes: Estonian small islands and islanders through three centuries.

Doctoral thesis, monograph Stockholm University, Faculty of Social Sciences,

Department of Human Geography.

Porteous, J. D. (1988). Topocide: The annihilation of place. In J. Eyles \& D. M. Smith (Eds.), Qualitative methods in human geography (pp. 75-93). Cambridge, U.K.: Polity Press. 
Potter, J. \& Wetherell, M. (1987). Discourse and social psychology; beyond attitudes and behaviour. London: Sage.

Prochansky, H. M., Fabian, A.K., \& Kaminoff. R. (1983). Place identity: physical world socialization of self. Journal of Environmental Psychology, 3, 57-83. https://doi.org/10.1016/S0272-4944(83)80021-8

Raadik, J. (2005). Fixed link and island: A study of community identity on Saaremaa Island Estonia. Unpublished master's thesis, Wageningen University, Wageningen, The Netherlands.

Rapley, M., \& Pretty, G.M.H. (1999). Playing Proscustes: the interactional production of a 'psychological sense of community'. Journal of Community Psychology, 27(6), 695-713. https://doi.org/10.1002/(SICI)1520-6629(199911)27:6<695::AID-JCOP5>3.0.CO;2-M

Relph, F. (1976). Place and placelessness. London: Pion.

Rowles. G.D. (1983). Place and personal identity in old age: Observations from Appalachia, Journal of Environmental Psychology, 3(4), 299-313. https://doi.org/10.1016/S02724944(83)80033-4

Said, E.W. (1978). Orientalism. New York: Pantheon.

Shamai, S. (1991). Sense of place: an empirical measurement. Geoforum, 22(3), 347-358. https://doi.org/10.1016/0016-7185(91)90017-K

Stamper, R., Liu, K., Hafkamp, M., \& Ades, Y. (2000). Understanding the roles of signs and norms in organizations: a semiotic approach to information systems design. Behaviour and Information Technology, 19(1), 15-27. https://doi.org/10.1080/014492900118768

Stedman, R., C. (2002). Towards a social psychology of place: predicting behaviour from placebased cognitions, attitude and identity. Environment and Behaviour, 34(5), 561-581. https://doi.org/10.1177/0013916502034005001

Trost, J. (1986). Statistically nonrepresentative stratified sampling: a sampling technique for qualitative studies. Qualitative sociology, 9(1), 54-57. https://doi.org/10.1007/BF00988249

Tuan, Y. (1977). Space and place: The perspective of experience. Minneapolis MN: University of Minnesota Press.

Tuan, Y. (1980). Rootedness versus sense of place. Landscape, 24(1), 3-8.

Tuan, Y. (1991). Language and the making of place: a narrative-descriptive approach. Annals of the Association of American Geographers, 81, 684-696. https://doi.org/10.1111/j.14678306.1991.tb01715.x

Twigger-Ross, C.L., \& Uzzel, D.L. (1996). Place and identity processes. Journal of Environmental Psychology, 16, 205-220. https://doi.org/10.1006/jevp.1996.0017

Vorkinn, M., \& Riese, H. (2001). Environmental concern in a local context: the significance of place attachment. Environment and Behaviour, 33(2), 249-263. https://doi.org/10.1177/00139160121972972

Wetherell, M., \& Potter, J. (1988). Discourse analysis and the identification of interpretative repertoires. In C. Antaki (Ed.), Analyzing everyday explanations: A casebook of methods, (pp. 168-183). Newbury Park, CA: Sage. 